\title{
Dietary curcumin supplementation attenuates inflammation, hepatic injury and oxidative damage in a rat model of intra-uterine growth retardation
}

\author{
Jintian He, Yu Niu, Fei Wang, Chao Wang, Tao Cui, Kaiwen Bai, Jingfei Zhang, Xiang Zhong, Lili Zhang \\ and Tian Wang* \\ College of Animal Science and Technology, Nanjing Agricultural University, Nanjing 210095, People's Republic of China
}

(Submitted 28 September 2017 - Final revision received 5 May 2018 - Accepted 24 May 2018 - First published online 25 July 2018)

\begin{abstract}
Rats with a normal birth weight (NBW) or intra-uterine growth retardation (IUGR) were fed basic diets (NBW and IUGR groups) or basic diets supplemented with curcumin (NC and IC groups) from 6 to 12 weeks. The body weight of IUGR rats was lower $(P<0 \cdot 05)$ than that of the controls. Rats with IUGR showed higher $(P<0.05)$ concentrations of TNF- $\alpha$, IL-1 $\beta$ and IL- 6 ; higher $(P<0.05)$ activities of aspartate aminotransferase (AST) and alanine aminotransferase (ALT) in their serum; and increased $(P<0 \cdot 05)$ concentrations of malondialdehyde (MDA), protein carbonyl (PC) and 8-hydroxy-2'-deoxyguanosine (8-OHDG) in the liver compared with the NBW rats. The livers of IUGR rats exhibited a lower $(P<0.05)$ superoxide dismutase activity and decreased $(P<0.05)$ metabolic efficiency of the hepatic glutathione redox cycle compared with those of the NBW rats. In response to dietary curcumin supplementation, concentrations of inflammatory cytokines and activities of AST and ALT in the serum and MDA, PC and 8-OHDG in the liver were lower $(P<0 \cdot 05)$, and the hepatic glutathione redox cycle in the liver was improved $(P<0.05)$ in the IC group than in the IUGR group. These results were associated with lower $(P<0.05)$ phosphorylated levels of the NF- $\kappa \mathrm{B}$ pathway and Janus kinase 2 (JAK2) and higher $(P<0.05)$ mRNA expression of genes involved in the nuclear factor, erythroid 2-like 2 ( Nfe2l2)/antioxidant response element ( $A R E$ ) pathway in the liver of the IC rats than that of the IUGR rats. Maternal undernutrition decreased birth weight and led to inflammation, oxidative damage and injury in rats. Curcumin appeared to be beneficial in preventing IUGR-induced inflammation, oxidative damage and injury by activating the expression of the NF- $\kappa \mathrm{B}$, JAK/STAT and $N f e 2 l 2 / A R E$ pathways in the liver.
\end{abstract}

\section{Key words: Intra-uterine growth retardation: Curcumin: Inflammation: Liver: Oxidative damage}

Researchers have observed that at least 13.7 million infants are born with a low birth weight each year, accounting for about $11 \%$ of newborns in developing countries ${ }^{(1)}$. The probability of intra-uterine growth retardation (IUGR) in developing countries is approximately six times higher than that in developed countries. IUGR is defined as growth and development of a fetus and/or its organ that is less than that of a normal fetus during gestation. The most notable and direct feature of IUGR neonates is the lower birth weight, mainly owing to placental insufficiency $^{(2)}$. During the critical stage of fetal growth and development, nutritional deficiencies may cause alterations in tissue and organ function, which has long-term effects ${ }^{(3)}$. Barker et $a l^{\left({ }^{(4)}\right.}$ originally stated the 'early' or 'fetal' origins of adult disease hypothesis. The hypothesis described that environmental factors, particularly the nutritional factor, acted during early life to programme the risks for the early onset of metabolic disease into adult life and premature death. It is obvious that IUGR has become a big problem for humans, especially in developing countries, and has adverse effects on children during their childhood and adulthood ${ }^{(5)}$. Numerous epidemiological studies of people from all over the world, including those in the USA, China, India and Australasia, have also strongly supported the hypothesis that IUGR could lead to a low birth weight initially, thus increasing the risk of developing metabolic diseases in adulthood ${ }^{(6)}$. Current data suggest that IUGR down-regulated the levels of proteins that regulated immune function and oxidative defence, and impaired liver function was found in newborn piglets with $\mathrm{IUGR}^{(7)}$. Results also suggested that a stronger pro-inflammatory bias existed in peripheral blood lymphocytes of women with a diagnosis of

Abbreviations: 8-OHDG, 8-hydroxy-2'-deoxyguanosine; ALT, alanine aminotransferase; AST, aspartate aminotransferase; GPX, glutathione peroxidase; GR, glutathione reductase; Gst, glutathione S transferase; Hmox1, haeme oxygenase 1; IC, intra-uterine growth retardation with curcumin supplementation; IUGR, intra-uterine growth retardation; JAK, Janus kinase; MDA, malondialdehyde; NBW, normal birth weight; NC, normal birth weight with curcumin supplementation; Nfe2l2, nuclear factor, erythroid 2-like 2; PC, protein carbonyl; SOD, superoxide dismutase; STAT3, signal transducer and activator of transcription 3 . 
$\mathrm{IUGR}^{(8)}$. Reports also showed that the hepatocytes of IUGR fetuses might suffer from oxidative stress, thereby decreasing their liver detoxifying abilities ${ }^{(7)}$. Although IUGR has emerged as a leading cause of neonatal morbidity and mortality, research on fetuses is extremely hard and complex during pregnancy. Thus, studies on IUGR are mainly focused on its postnatal treatment.

Curcumin $\left(\mathrm{C}_{21} \mathrm{H}_{20} \mathrm{O}_{6}\right)$, a yellow pigment from turmeric (Curcuma longa), is a naturally occurring phenolic compound, which is widely used in food, beverages, medicines and so forth $^{(9)}$. Curcumin, first described in 1910 by Lampe and Milobedeska, is the most active ingredient in turmeric and accounts for $2-5 \%$ of this spice ${ }^{(10)}$. Previous studies have found that curcumin plays an important role in the inhibition of platelet aggregation, tumorigenesis, oxidation, inflammatory cytokines and myocardial infarction ${ }^{(11)}$. Curcumin is also known to possess the capacity for anti-inflammatory ${ }^{(12)}$, antioxidant ${ }^{(13)}$, anticancer, anti-tumour activities and has other potential protective effects against various diseases ${ }^{(14)}$. In human applications, it has been demonstrated to be safe at dosages of up to $8 \mathrm{~g} / \mathrm{d}^{(15)}$. In recent years, researchers have revealed that curcumin had protective effects against oxidative stress through multiple mechanisms, including the elevation of antioxidant enzyme activity, attenuation of mitochondrial dysfunction and reduction in liver injury ${ }^{(16,17)}$. Studies also revealed that diets supplemented with $0.05 \%$ curcumin could attenuate oxidative stress and inflammation in rats ${ }^{(18)}$.

The maternal rat used as an animal model to create IUGR newborns has been widely recognised ${ }^{(19)}$. During the selected period of pregnancy, maternal nutrition deficiencies or malnutrition have been illustrated to lead to growth retardation of rats ${ }^{(20)}$. It is generally known that IUGR can have harmful effects. However, more effective nutritional treatments are yet to be studied. To the best of our knowledge, the studies on the effects of curcumin on IUGR are limited. To test this hypothesis, we chose newborn rats with a low birth weight as the IUGR models to investigate whether IUGR could induce inflammation, oxidative damage and injury in the liver. We also observed the effects of dietary $400 \mathrm{mg}$ curcumin/kg diet supplementation on IUGR.

\section{Methods}

\section{Curcumin preparation}

The curcumin used in this study was kindly provided by the Kehu Bio-technology Research Center.

\section{Animal experiment design}

The experimental design and procedures were approved by the Institutional Animal Care and Use Committee of Nanjing Agricultural University following the requirements of the Regulations for the Administration of Affairs Concerning Experimental Animals of China. The feed restriction method was used for maternal rats during pregnancy to create an IUGR mode based on a previous study ${ }^{(19)}$. This method was easily controlled by us and based on our previous experiences with bilateral artery ligation and protein restriction models. First-time-pregnant Sprague-Dawley rats (Nanjing Qinglongshan Experiment
Animal Center) were housed in a facility at a constant temperature and humidity and a controlled $12 \mathrm{~h}$ light- $12 \mathrm{~h}$ dark cycle. At day 10 of gestation, rats were provided either a diet of standard laboratory chow (LabDiet 5001) ( $n$ 12) ad libitum or a $50 \%$ feed-restricted ( $n$ 12) diet determined by the quantification of normal feed intake in ad libitum-fed rats.

In Experiment 1, maternal rats gave birth normally, and birth weights of newborns were recorded on day 1 of postnatal life and divided into normal or IUGR groups. Mice were limited to 10/litter to normalise rearing (average 11.83 and 12.1 mice/litter in normal and IUGR groups, respectively). During the 21-day lactation period, each litter of mice from the normal or IUGR group was nursed by their own maternal rats. At 3 weeks of age, offspring in each litter were weaned and housed individually until they were 6 weeks old. Each litter from the normal and IUGR groups was weighed, and the weight of an individual pup was calculated from the group (i.e. litter weight/number of pups). The weights of pups were recorded at 1, 21, 28, 35 and $42 \mathrm{~d}$ of age.

In Experiment 2, at 6 weeks of age, twenty-four female rats with nearly equal body weights (within each group) were allocated to the normal birth weight (NBW), NBW with curcumin supplementation (NC), IUGR and IUGR with curcumin supplementation (IC) groups (one rat per litter, $n$ 6/group), respectively. The rats were allowed water and a standard granulated diet (AIN-93 diet) ${ }^{(21)}$ ad libitum. During the entire experimental period, rats in the NC and IC groups were fed a standard diet supplemented with $400 \mathrm{mg}$ curcumin/ $\mathrm{kg}$. Curcumin was added to the feed before it was made into pellets. The light regimen was a $12 \mathrm{~h}$ light -12 hdark cycle and the temperature was maintained at $22 \pm 2^{\circ} \mathrm{C}$. Body weights of each group were recorded at $7,8,9$, 10, 11 and 12 weeks of age. At 12 weeks of age, all rats were fasted overnight, and blood was collected by cardiac puncture after anaesthesia. Serum was obtained from the blood by centrifugation for $15 \mathrm{~min}$ at $3000 \mathrm{~g}$ at $4^{\circ} \mathrm{C}$. Liver tissue was removed after death, weighed and snap-frozen in liquid $\mathrm{N}_{2}$ and then stored at $-80^{\circ} \mathrm{C}$ for further analysis. A portion of liver tissue (the same area for each sample) was removed and fixed in formalin for histologic assessment.

\section{Analysis of serum TNF- $\alpha, I L-1 \beta$ and IL-6}

Concentrations of TNF- $\alpha$, IL- $1 \beta$ and IL- 6 in the serum were determined by ELISA kits from Shanghai YILI Biological Technology Co., Ltd.

\section{Analysis of serum aminotransferase activities}

Activities of serum aspartate aminotransferase (AST) and alanine aminotransferase (ALT) were measured via the enzymatic kinetic method using an automatic biochemistry analyser (SELECTA XL; Vital Scientific) according to the manufacturer's $\operatorname{protocol}^{(16)}$.

\section{Liver histologic evaluation}

Liver tissue specimens from the right lobe were fixed immediately in $10 \%$ formalin, embedded in paraffin and $6-\mu \mathrm{m}$ sections were cut and stained with haematoxylin-eosin (H\&E) ${ }^{(22)}$. After 
H\&E staining, a morphologic evaluation was carried out using a light microscope (Nikon ECLIPSE 80i; Nikon Corporation). The section of each animal was counted at least three times.

\section{Analysis of lipid peroxidation, protein and DNA oxidation levels}

Lipid peroxidation levels were expressed by malondialdehyde (MDA) concentration, which is a byproduct of lipid peroxidation. Concentrations of MDA in the liver were determined by an assay kit (Nanjing Jiancheng Bioengineering Institute). Protein oxidation in the liver was estimated via the concentration of protein carbonyl (PC) according to a previous study ${ }^{(23)}$. For the measurement of endogenous oxidative DNA damage, 8-hydroxy2'-deoxyguanosine (8-OHDG) was used as a biomarker. Concentrations of 8-OHDG in the liver were determined by ELISA kits from Shanghai YILI Biological Technology Co., Ltd.

\section{Assay of antioxidant enzyme activities in the serum and liver}

The liver samples from $-80^{\circ} \mathrm{C}$ were homogenised with $0 \cdot 86 \%$ $(\mathrm{w} / \mathrm{v})$ ice-cold physiological saline or tissue homogenate provided by the corresponding diagnostic kit (Nanjing Jiancheng Bioengineering Institute) according to the instructions of the manufacturer. Liver samples were homogenised using an UltraTurrax homogenizer (Tekmar) at $13500 \boldsymbol{g}$ for $1 \mathrm{~min}$ in ice-cold water. Then, the homogenate was centrifuged at $3000 \mathbf{g}$ for $15 \mathrm{~min}$ at $4^{\circ} \mathrm{C}$, and the supernatant was analysed quickly. All results were normalised to total protein concentrations in each sample for inter-sample comparisons. The levels of GSH and glutathione peroxidase (GPX) in the serum, and activities of superoxide dismutase (SOD), total antioxidant capacity (T-AOC), glutathione reductase (GR), GPX and concentrations of GSH and GSSG in the liver were determined using assay kits (Nanjing Jiancheng Bioengineering Institute) according to the manufacturer's instructions.

\section{Assay of gene expression}

Total RNA from the liver samples stored at $-80^{\circ} \mathrm{C}$ was isolated using the TRIzol reagent (Invitrogen). The determination of
RNA content, mRNA quantification and real-time PCR (Applied Biosystems) were performed according to previously described methods ${ }^{(24)}$. The primer sequences for the target and housekeeping genes (Tnfa, Il1b, Il , nuclear factor, erythroid 2-like 2 (Nfe2l2), NAD(P)H dehydrogenase, quinone 1 (Nqo1), haeme oxygenase 1 (Hmox1), glutathione $S$ transferase (Gst), glutathione peroxidase 1 (Gpx1), superoxide dismutase 1 (Sod1) and $\beta$-actin $(A c t b))$ used for real-time PCR are listed in Table 1. Gapdh was also used as a control gene to normalise the expression of target genes. Briefly, a reaction system of $20 \mu \mathrm{l}$ was composed of $0.4 \mu \mathrm{l}$ of forward primers, $0.4 \mu \mathrm{l}$ of reverse primers, $0.4 \mu \mathrm{l}$ of ROX Reference Dye, $10 \mu \mathrm{l}$ of SYBR Premix Ex Taq (TaKaRa Biotechnology Co. Ltd), $6 \cdot 8 \mu \mathrm{l}$ of double-distilled water and $2 \mu \mathrm{l}$ of complementary DNA. The $2^{-\Delta \Delta C_{t}}$ method was used to calculate relative levels of mRNA expression after normalisation with housekeeping genes ${ }^{(25)}$. The values for the NBW group were used for calibration.

\section{Western blotting}

Antibodies against total NF- $\kappa \mathrm{B}$ (dilution 1:500) and phosphorylated NF- $\kappa \mathrm{B}$ (dilution 1:500) were purchased from Bioworld. Antibodies against total Janus kinase 2 (JAK2, dilution 1:1000), signal transducer and activator of transcription 3 (STAT3, dilution 1:1 000), $\mathrm{I} \kappa \mathrm{B} \alpha$ (dilution 1:500) and phosphorylated JAK2 (dilution 1:1 000), STAT3 (dilution 1:500) and $\mathrm{I} \kappa \mathrm{B} \alpha$ (dilution 1:1 000) were purchased from Abcam. The protein (total, nuclear or cytoplasmic) of the liver was extracted using assay kits according to the manufacturer's instructions (Beyotime). The protein content of the sample was assayed using the BCA Protein Assay Kit (Beyotime). For Western blotting analyses, $60 \mu \mathrm{g}$ of protein from each sample was subjected to sodium dodecylsulphate-PAGE. After electrophoresis, proteins were separated and transferred to polyvinylidene difluoride membranes. The membranes were blocked with blocking buffer ( $5 \%$ non-fat dry milk) for $12 \mathrm{~h}$ at $4{ }^{\circ} \mathrm{C}$. The membranes were probed with appropriate primary and secondary antibodies (horseradish-peroxidase-conjugated goat anti-rabbit Ig G; Bioworld; 1:10 000 dilution in $1 \times$ TBS with $0 \cdot 1 \%$ Tween 20). The blots were detected using enhanced chemiluminescence reagents (ECL-Kit; Beyotime) followed by

Table 1. Primer sequences used for quantitative real-time PCR assays

\begin{tabular}{|c|c|c|c|c|}
\hline \multirow[b]{2}{*}{ Primers } & \multirow[b]{2}{*}{ Accession no. } & \multicolumn{2}{|c|}{ Sequences } & \multirow[b]{2}{*}{ Product size $(b p$} \\
\hline & & $\mathrm{F}$ & $\mathrm{R}$ & \\
\hline Tnfa & XM_008772775.2 & GAACTCAGCGAGGACACCAA & GCCAGTGTATGAGAGGGACG & 124 \\
\hline$\| 1 b$ & NM_031512.2 & GACTTCACCATGGAACCCGT & GGAGACTGCCCATTCTCGAC & 104 \\
\hline 116 & NM_012589.2 & СССААСТTССААТGСТСТССТ & GGATGGTCTTGGTCCTTAGCC & 71 \\
\hline $\mathrm{Nfe} 2 \mathrm{l2}$ & NM_031789.2 & AGCAAGACTTGGGCCACTTA & GATGGAGGTTTCTGTCGTTTTC & 78 \\
\hline Nqo1 & NM_017000.3 & TGGAGACTGTCTGGGAGGAG & TCCTGCCTGGAAGTTTAGGT & 74 \\
\hline Hmox 1 & NM 012580.2 & TAACCAGGATCTCCCCAAGA & TTAGAGTGCTGTGGCAGGTG & 73 \\
\hline Gst & J037̄̄52.1 & TCTTGTTGGCAACCAACTCA & AGTCAGACAGCACAGGAGCA & 92 \\
\hline Gpx1 & NM_030826.4 & AAGGCTCACCCGCTCTTTAC & ACACCGGGGACCAAATGATG & 106 \\
\hline Sod1 & NM_017050.1 & AGGGCGTCATTCACTTCGAG & CCCATGCTCGCCTTCAGTTA & 89 \\
\hline Actb & NM_031144.3 & ATGCTGCGTCTGGACTG & CTCCAGTGTGGTGAA & 85 \\
\hline
\end{tabular}

F, forward; R, reverse; Nfe2I2, nuclear factor, erythroid 2-like 2; Nqo1, NAD(P)H dehydrogenase, quinone 1; Hmox1, haeme oxygenase 1; Gst, glutathione S transferase; Gpx1, glutathione peroxidase 1; Sod1, superoxide dismutase 1; Actb, $\beta$-actin. 
autoradiography. Photographs of the membranes were taken using the Luminescent Image Analyzer LAS-4000 system (Fujifilm Co.) and quantified by the Gel-Pro Analyzer 4.0 software (Media Cybernetics).

\section{Statistical analysis}

Body weights of NBW and IUGR mice at $1 \mathrm{~d}$ and from 1 to 6 weeks of age were analysed using unpaired, independent $t$ tests. Body weights from 6 to 12 weeks of age and measurements at 12 weeks of age were analysed using a two-way ANOVA. The classification variables were birth weight $(\mathrm{NBW}+$ $\mathrm{NC} \times \mathrm{IUGR}+\mathrm{IC})$, diet $(\mathrm{NBW}+\mathrm{IUGR} \times \mathrm{NC}+\mathrm{IC})$ and the interaction between birth weight and diet $(\mathrm{NBW} \times \mathrm{NC} \times \mathrm{IUGR} \times \mathrm{IC})$. A Tukey's post hoc analysis was used to determine the differences between the four groups when a statistically significant birth weight $\times$ diet interaction was observed. SPSS 17.0 (SPSS Inc.) was used for these analyses. A probability level of $P<0.05$ was considered statistically significant, and $P<0.01$ was considered very significant. Data are presented as means and standard deviations.

\section{Results}

\section{Growth analysis}

Offspring of IUGR rats were born smaller $(P=0 \cdot 005)$ than those of NBW rats $(5.546(\mathrm{sD} 0.264) v .6 .314$ (SD 0.358) g; Fig. 1(a)) and their body weights remained lower than those of the NBW group at $3,4,5$ and 6 weeks of age $(P=0.127, P=0.062, P=0.481$ and $P<0.001$, respectively). Body weights of rats in NBW and IUGR groups increased at $10(242.967 \quad(\mathrm{SD}$ 19.242) $v$. 237.333 (sD 12.138) g, $P>0.05 ; 225.533$ (sD 8.454) v. 221.100 (sD 9.291) g, $P>0.05)$ and 11 weeks (252.867 (sD 19.307) $v . \quad 247.267$ (sD 14.418) g, $P>0.05 ; 236.933$ (sD 9.915) v. $230 \cdot 283$ (sD 12.666) g, $P>0.05$ ) owing to dietary curcumin supplementation (Fig. 1(b)).

\section{Relative weight of liver}

At 12 weeks of age, liver weights of IUGR rats were obviously lower $(P<0.05)$ than those of NBW rats (Table 2$)$. Curcumin treatment did not improve $(P<0.05)$ liver weight or relative liver weight.

\section{Levels of serum inflammation cytokines}

IUGR rats exhibited significantly higher $(P<0.05)$ concentrations of serum TNF- $\alpha$, IL- $1 \beta$ and IL- 6 compared with NBW rats (Fig. 2(A)-(C)). Curcumin supplementation reduced the concentrations of serum TNF- $\alpha(P=0 \cdot 077)$, IL- $\beta(P=0 \cdot 007)$ and IL-6 $(P=0.002)$ in NBW or IUGR rats. In addition, a birth weight $\times$ dietary interaction effect $(P<0.05)$ was noted for concentrations of TNF- $\alpha$ and IL- 6 in the liver. There were no significant differences in the concentrations of serum inflammation cytokines among NBW, NC and IC groups $(P>0.05)$.

\section{Activities of serum aspartate aminotransferase and alanine aminotransferase}

The activity of serum AST was higher in the IUGR group $(P>0.05)$ than in the NBW group (Fig. 3(A)). Dietary curcumin supplementation significantly decreased the activity of serum AST in the IUGR group $(P<0 \cdot 05)$. The activity of serum ALT was higher in the IUGR group than in the NBW group $(P<0.05)$ (Fig. 3(B)). Because of dietary curcumin supplementation, the activity of ALT was significantly lower in the NC and IC groups than in the NBW and IUGR groups $(P<0 \cdot 01)$.

\section{Liver histological changes}

Normal histologic structures were observed in the liver of NBW and NC rats (Fig. 4(a) and (b)). In the liver sections of IUGR rats, vacuolisation and cell oedema were prevalent in the hepatocytes, and fat cells showed signs of mild denaturation (Fig. 4(c)). In the IC group, vacuolisation was significantly reduced and no fat cells were observed (Fig. 4(d)).

\section{Hepatic lipid peroxidation, protein and DNA oxidation levels}

The concentrations of MDA, PC and 8-OHDG in the liver of IUGR rats were significantly higher $(P<0.05)$ than those of
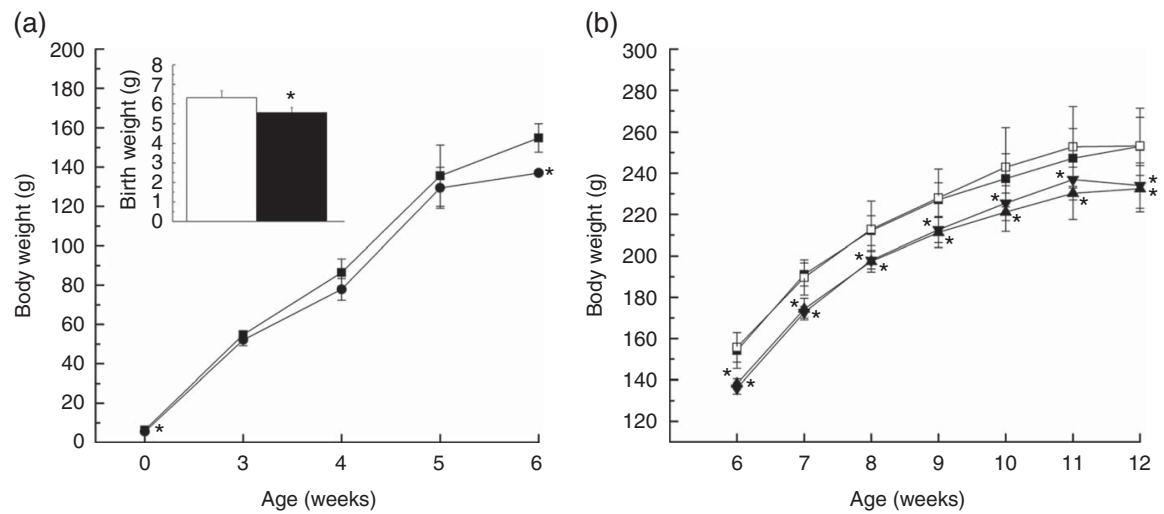

Fig. 1. Growth analysis of offspring with normal body weights (NBW) or intra-uterine growth retardation (IUGR) during the early period of life (a) and diets supplemented with curcumin (Cur) from 6 to 12 weeks of age (b). Values are means and standard deviations. a: $\square$ and $\longrightarrow$ - NBW; $\square$ and $\longrightarrow-$, IUGR; b: $\longrightarrow$, NBW; $\square-, N B W+$ Cur; $\longrightarrow$, IUGR; $\longrightarrow$, IUGR + Cur. Body weights of NBW and IUGR mice at $1 \mathrm{~d}$ of age and from 1 to 6 weeks of age were analysed using unpaired independent $t$ tests. Body weights from 6 to 12 weeks of age were analysed by using two-way ANOVA, $n 6$. ${ }^{*}$ Significant difference was observed $(P<0.05)$. 
Table 2. Effect of curcumin on the liver weight and liver relative weight of rats with intra-uterine growth retardation (IUGR) (12 weeks of age)* (Mean values and standard deviations; $n 6$ per group)

\begin{tabular}{|c|c|c|c|c|c|c|c|c|c|c|c|}
\hline \multirow[b]{3}{*}{ Items } & \multicolumn{8}{|c|}{ Experiment groups } & & & \\
\hline & \multicolumn{2}{|c|}{ NBW } & \multicolumn{2}{|c|}{ NC } & \multicolumn{2}{|c|}{ IUGR } & \multicolumn{2}{|c|}{ IC } & \multicolumn{3}{|c|}{$P$} \\
\hline & Mean & SD & Mean & SD & Mean & SD & Mean & SD & $B$ & $D$ & $B \times D$ \\
\hline BW (g) & $253.08^{a}$ & $14 \cdot 12$ & $253 \cdot 25^{a}$ & 18.08 & $232 \cdot 50^{b}$ & $11 \cdot 23$ & $234.00^{b}$ & 11.00 & $<0.01$ & 0.89 & 0.91 \\
\hline Liver $(g)$ & $10 \cdot 35^{\mathrm{a}}$ & $1 \cdot 11$ & $9 \cdot 16^{b}$ & 0.92 & $8.90^{c}$ & 0.73 & $8.44^{d}$ & 0.56 & $<0.01$ & 0.03 & 0.31 \\
\hline LRW $(g / 100 \mathrm{~g} \mathrm{BW}) \dagger$ & $4.09^{a}$ & 0.35 & $3.61^{\mathrm{b}}$ & 0.20 & $3.83^{a}$ & 0.20 & $3 \cdot 61^{\mathrm{b}}$ & 0.09 & 0.16 & $<0.01$ & 0.18 \\
\hline
\end{tabular}

NBW, normal birth weight rats; NC, normal birth weight rats fed diets supplemented with $400 \mathrm{mg} / \mathrm{kg}$ curcumin; IC, IUGR rats fed diets supplemented with $400 \mathrm{mg} / \mathrm{kg}$ curcumin; $B$, birth weight; $D$, dietary curcumin supplementation; $B \times D$, interaction between the corresponding parameters; BW, body weight; LRW, relative weight of liver.

$\mathrm{a}, \mathrm{b}, \mathrm{c}, \mathrm{d}$ Mean values within a row with unlike superscript letters were significantly different when a significant interaction was observed $(P<0.05)$.

* Data were analysed by using two-factor ANOVA and Duncan's post hoc testing, where appropriate.

$\dagger$ The relative weight of liver is equal to the liver weight to per $100 \mathrm{~g} \mathrm{BW}$.

(A)

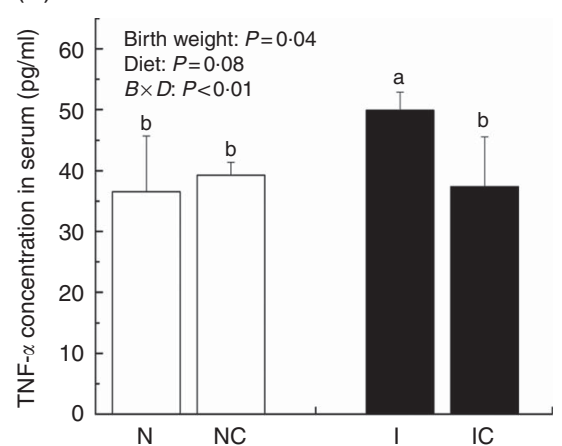

(B)

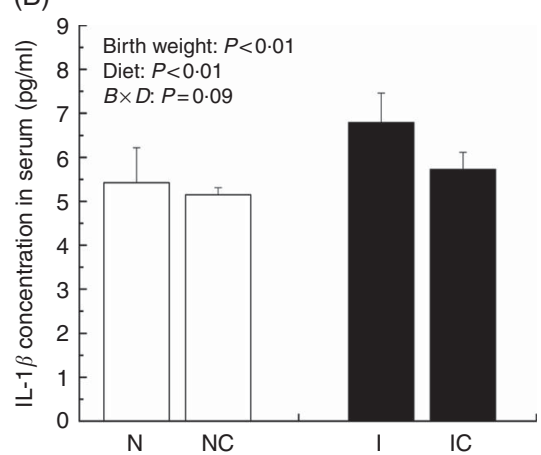

(C)

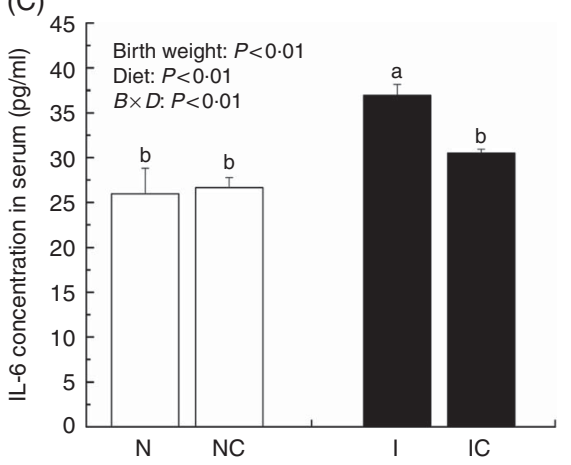

Fig. 2. Concentrations of TNF- $a(A), I L-1 \beta(B)$ and IL-6 (C) in the serum of normal birth weight rats (N), normal birth weight rats supplemented with curcumin (NC), intra-uterine growth retardation (IUGR) rats (I) and IUGR rats supplemented with curcumin (IC) (12 weeks of age). Values are means ( $n$ 6) and standard deviations. $\square$, Normal birth weight; $\square$, IUGR; $B$, birth weight; $D$, diet; $B \times D$, interaction between the corresponding parameters. Data were analysed by using two-way ANOVA. ${ }_{\mathrm{a}, \mathrm{b}}$ Mean values with unlike letters were significantly different when a significant interaction was observed $(P<0.05)$.

(A)

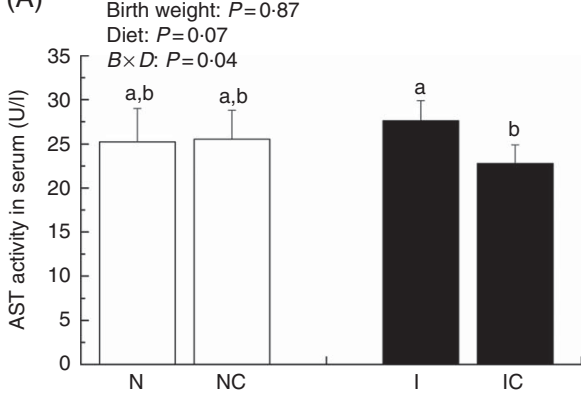

(B)

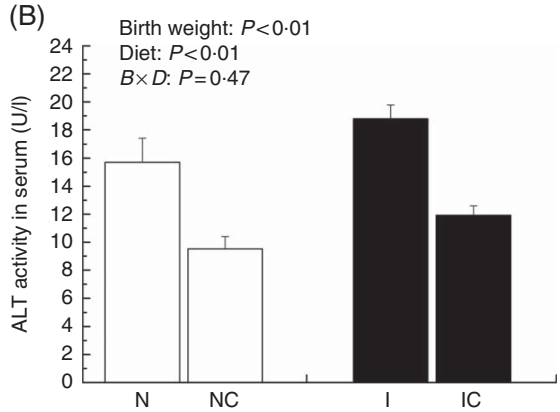

Fig. 3. Activities of aspartate aminotransferase (AST) (A) and alanine aminotransferase (ALT) (B) in the serum of normal birth weight rats (N), normal birth weight rats supplemented with curcumin (NC), intra-uterine growth retardation (IUGR) rats (I) and IUGR rats supplemented with curcumin (IC) (12 weeks of age). Values are means $(n 6)$ and standard deviations. $\square$, Normal birth weight; $\square$, IUGR; $B$, birth weight; $D$, diet; $B \times D$, interaction between the corresponding parameters. Data were analysed by using two-way ANOVA. ${ }^{a, b}$ Mean values with unlike letters were significantly different when a significant interaction was observed $(P<0.05)$.

NBW rats (Fig. 5(A)-(C)). In addition, a birth weight $\times$ dietary interaction effect was noted for liver concentrations of MDA and 8-OHDG in rats. Dietary curcumin supplementation significantly decreased the concentrations of MDA, PC and 8-OHDG in the liver of IUGR rats $(P<0.05)$.

\section{Hepatic antioxidant defence capacity}

The IUGR group showed lower concentrations $(P<0 \cdot 01)$ of GSH and activity of GPX $(P<0 \cdot 1)$ in the serum of rats compared with the NBW group (Table 3). In the IC group, the concentration of GSH and activity of GPX in the serum of rats were higher $(P<0 \cdot 01)$ than those in the IUGR group. However, those of the NBW group were higher $(P<0 \cdot 01)$ than those of the NC group. A birth weight $\times$ dietary interaction effect was noted for activities of SOD, GR and GPX; concentrations of GSH and GSSG; and the value of GSSG:GSH in the liver of rats. The IUGR group showed lower $(P<0.05)$ SOD, GR and GPX activities; lower GSH concentrations; and higher $(P<0.05)$ GSSG concentration and GSSG: GSH value in the liver. In the IC group, the activity of GR and 

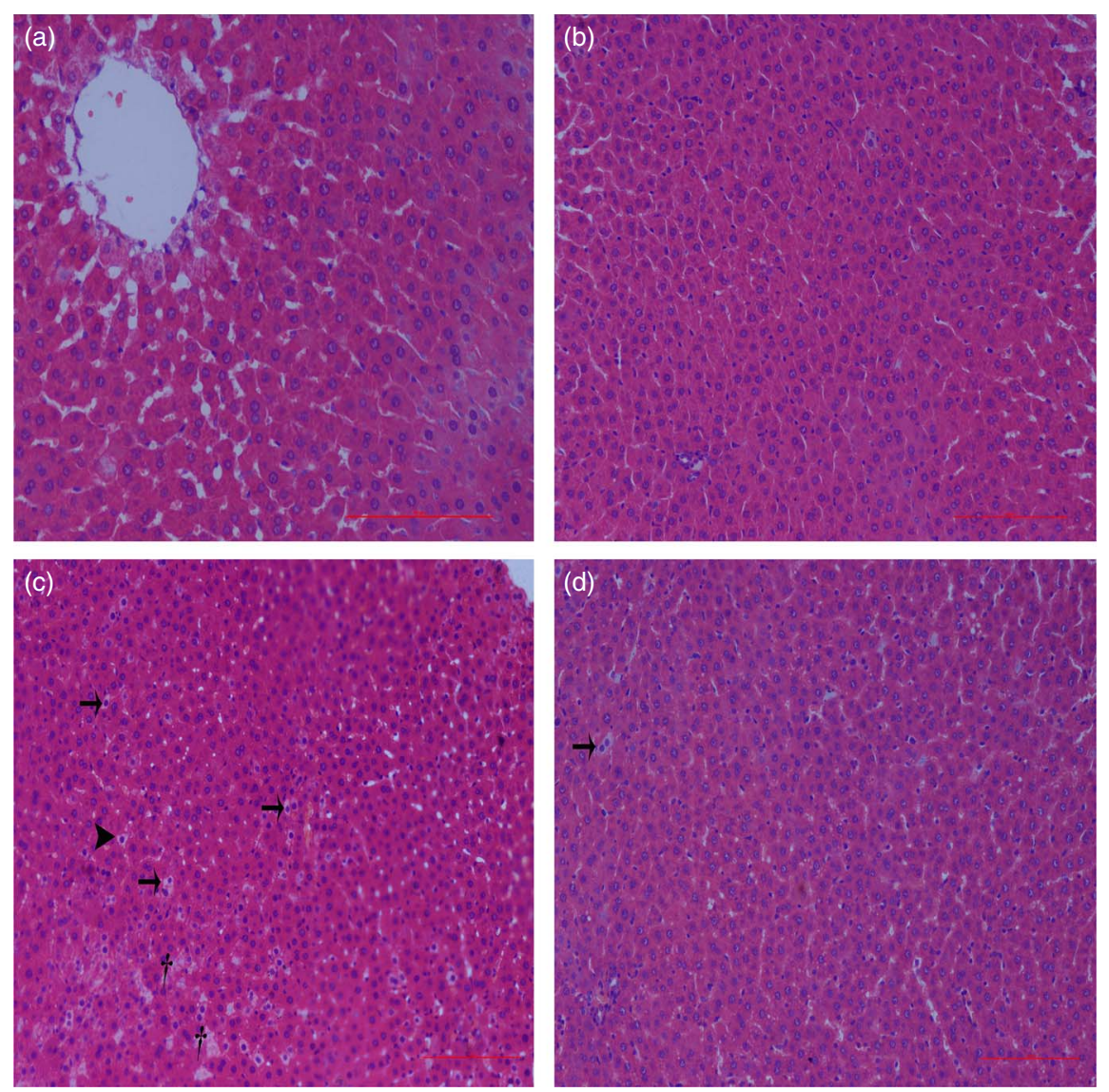

Fig. 4. Light microscopy of liver tissue in different groups (200x magnification): (a) normal birth weight rats, (b) normal birth weight rats supplemented with curcumin, (c) intra-uterine growth retardation rats and (d) intra-uterine growth retardation rats supplemented with curcumin. Haematoxylin-eosin, scale bar $=100 \mu \mathrm{m}$. $†$ Vacuole; $\rightarrow$, fat cell; $\rightarrow$, cellular oedema.

(A)

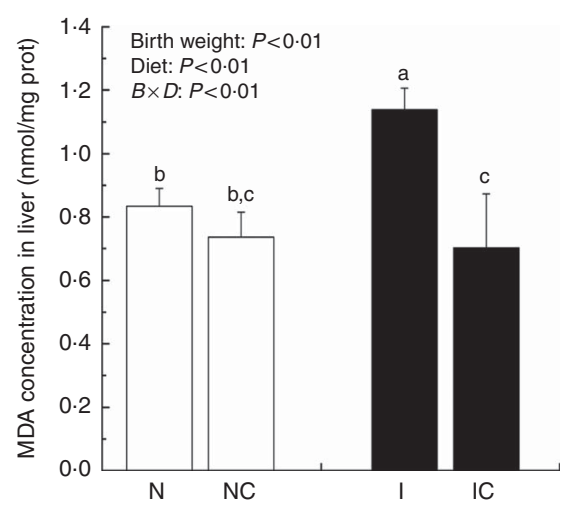

(B)

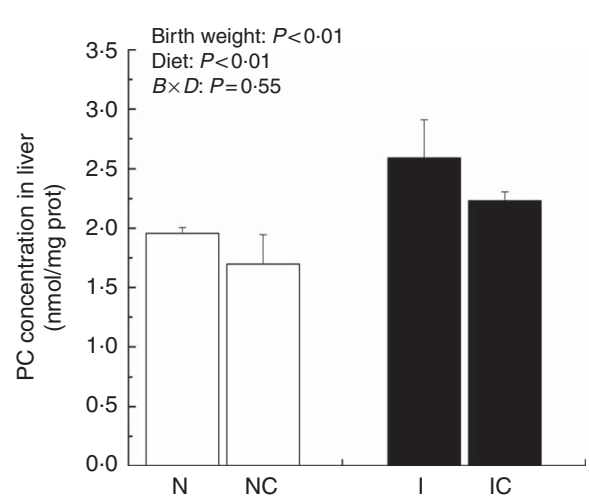

(C)

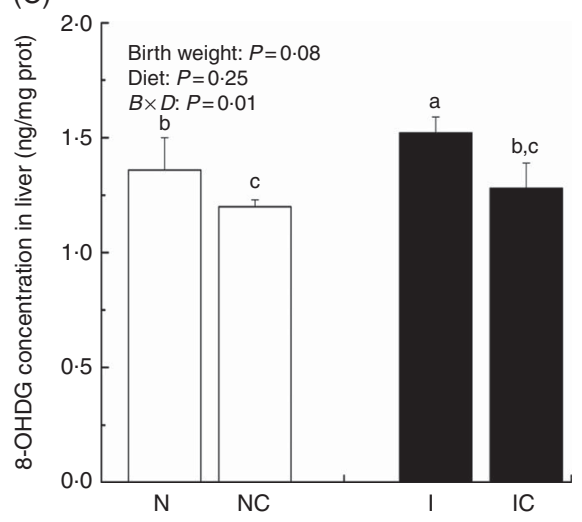

Fig. 5. Concentrations of malondialdehyde (MDA) (A), protein carbonyl (PC) (B) and 8-hydroxy-2'-deoxyguanosine (8-OHDG) (C) in the liver of normal birth weight rats $(\mathrm{N})$, normal birth weight rats supplemented with curcumin (NC), intra-uterine growth retardation (IUGR) rats (I) and IUGR rats supplemented with curcumin (IC) (12 weeks of age). Values are means $(n 6)$ and standard deviations. $\square$, Normal birth weight; $\square$, IUGR; $B$, birth weight; $D$, diet; $B \times D$, interaction between the corresponding parameters. Data were analysed by using two-way ANOVA. ${ }^{\mathrm{a}, \mathrm{b}, \mathrm{c}}$ Mean values with unlike letters were significantly different when a significant interaction was observed $(P<0.05)$.

concentration of GSH in the liver were higher $(P<0 \cdot 05)$, and the concentration of GSSG and value of GSSG:GSH in the liver were lower $(P<0.05)$ compared with those in the IUGR group. The NC group had lower $(P<0.05)$ activities of SOD, GR and GPX; decreased concentrations of GSH $(P<0.05)$; and a higher $(P<0.05)$ GSSG:GSH value in the liver than in the NBW group.

\section{Gene expression}

In the liver of the IUGR group, the mRNA expression level for Il6 was higher $(P<0.05)$ and the mRNA expression levels for Gst $(P<0.05)$ and Nfe2l2, Hmox1, Gpx1 and Sod1 $(P>0.05)$ were lower than those of the NBW group (Table 4). Dietary 
Table 3. Effect of curcumin on the hepatic antioxidant defence capacity of rats with intra-uterine growth retardation (IUGR) (12 weeks of age)* (Mean values and standard deviations; $n 6$ per group)

\begin{tabular}{|c|c|c|c|c|c|c|c|c|c|c|c|}
\hline \multirow[b]{3}{*}{ Items } & \multicolumn{8}{|c|}{ Experiment groups } & & & \\
\hline & \multicolumn{2}{|c|}{ NBW } & \multicolumn{2}{|c|}{$\mathrm{NC}$} & \multicolumn{2}{|c|}{ IUGR } & \multicolumn{2}{|c|}{ IC } & \multicolumn{3}{|c|}{$P$} \\
\hline & Mean & SD & Mean & SD & Mean & SD & Mean & SD & $B$ & $D$ & $B \times D$ \\
\hline \multicolumn{12}{|l|}{ Serum } \\
\hline $\mathrm{GSH}(\mu \mathrm{mol} / \mathrm{l})$ & $15 \cdot 02$ & $2 \cdot 13$ & 11.69 & $1 \cdot 26$ & $5 \cdot 04$ & 0.98 & $8 \cdot 70$ & 0.98 & $<0.01$ & $<0.01$ & 0.78 \\
\hline GPX (U/ml) & $462 \cdot 67$ & 39.97 & $369 \cdot 78$ & 25.95 & $319 \cdot 11$ & $43 \cdot 15$ & 412.44 & $46 \cdot 42$ & $<0.01$ & $<0.01$ & 0.99 \\
\hline \multicolumn{12}{|l|}{ Liver } \\
\hline T-AOC (U/mg prot) & $0.67^{a, b}$ & 0.08 & $0.72^{\mathrm{a}}$ & 0.10 & $0.61^{b}$ & 0.05 & $0.67^{a, b}$ & 0.08 & 0.11 & 0.12 & 0.92 \\
\hline SOD (U/mg prot) & $64.47^{a}$ & $2 \cdot 23$ & $57 \cdot 42^{\mathrm{b}}$ & $4 \cdot 71$ & $59 \cdot 06^{b}$ & 1.52 & $61 \cdot 82^{a, b}$ & $5 \cdot 24$ & 0.75 & 0.18 & $<0.01$ \\
\hline GSH ( $\mu \mathrm{mol} / \mathrm{g}$ prot $)$ & $29 \cdot 37^{a}$ & 2.50 & $17 \cdot 22^{b}$ & 2.50 & $11.45^{\mathrm{C}}$ & $3 \cdot 19$ & $30 \cdot 91^{a}$ & 1.80 & 0.06 & $<0.01$ & $<0.01$ \\
\hline GSSG ( $\mu \mathrm{mol} / \mathrm{g}$ prot $)$ & $35 \cdot 19^{b, c}$ & 4.51 & $36 \cdot 81^{\mathrm{b}}$ & $5 \cdot 25$ & $44 \cdot 43^{a}$ & 2.08 & $30 \cdot 98^{c}$ & $4 \cdot 21$ & 0.33 & $<0.01$ & $<0.01$ \\
\hline GSSG:GSH & $1 \cdot 18^{\mathrm{C}}$ & 0.05 & $2 \cdot 19^{b}$ & 0.34 & $4 \cdot 18^{a}$ & 0.71 & $1.05^{c}$ & 0.08 & $<0.01$ & $<0.01$ & $<0.01$ \\
\hline GR (U/mg prot) & $19 \cdot 47^{\mathrm{a}}$ & 0.21 & $16 \cdot 14^{\mathrm{b}}$ & $2 \cdot 82$ & $14 \cdot 48^{\mathrm{b}}$ & 0.24 & $18 \cdot 04^{a}$ & 0.71 & 0.02 & 0.84 & $<0.01$ \\
\hline GPX (U/mg prot) & $670 \cdot 20^{a}$ & $20 \cdot 34$ & $588 \cdot 61^{b}$ & 54.86 & $532 \cdot 28^{C}$ & $36 \cdot 16$ & $554 \cdot 45^{c}$ & $24 \cdot 35$ & $<0.01$ & 0.06 & $<0.01$ \\
\hline
\end{tabular}

NBW, normal birth weight rats; NC, normal birth weight rats fed diets supplemented with $400 \mathrm{mg} / \mathrm{kg}$ curcumin; IC, IUGR fed diets supplemented with $400 \mathrm{mg} / \mathrm{kg}$ curcumin; $B$, birth weight; $D$, dietary curcumin supplementation; $B \times D$, interaction between the corresponding parameters; GPX, glutathione peroxidase; T-AOC, total antioxidant capacity; SOD, superoxide dismutase; GR, glutathione reductase; I, IUGR.

a,b,c Mean values within a row with unlike superscript letters were significantly different when a significant interaction was observed $(P<0.05)$.

* Data were analysed by using two-factor ANOVA and Duncan's post hoc testing, where appropriate.

Table 4. Effect of curcumin on the hepatic gene expressions of rats with intra-uterine growth retardation (IUGR) (12 weeks of age) ${ }^{*}$ (Mean values and standard deviations; $n 6$ per group)

\begin{tabular}{|c|c|c|c|c|c|c|c|c|c|c|c|}
\hline \multirow[b]{3}{*}{ Items } & \multicolumn{8}{|c|}{ Experiment groups } & & & \\
\hline & \multicolumn{2}{|c|}{ NBW } & \multicolumn{2}{|c|}{$\mathrm{NC}$} & \multicolumn{2}{|c|}{ IUGR } & \multicolumn{2}{|c|}{ IC } & \multicolumn{3}{|c|}{$P$} \\
\hline & Mean & SD & Mean & SD & Mean & SD & Mean & SD & $B$ & $D$ & $B \times D$ \\
\hline Tnfa & 1.00 & 0.00 & 1.04 & 0.16 & 1.33 & 0.06 & 1.09 & 0.30 & 0.87 & 0.27 & 0.12 \\
\hline$\| 11 b$ & 1.00 & 0.00 & 0.92 & 0.04 & 1.21 & 0.29 & 0.99 & 0.17 & 0.96 & 0.04 & 0.33 \\
\hline 116 & 1.00 & 0.00 & 1.00 & 0.25 & 2.05 & 0.10 & 1.50 & 0.08 & 0.02 & 0.13 & 0.12 \\
\hline Nfe2l2 & 1.00 & 0.00 & 1.08 & 0.32 & 0.76 & 0.16 & 0.97 & 0.258 & 0.53 & 0.02 & 0.30 \\
\hline Nqo1 & $1.00^{\mathrm{b}}$ & 0.00 & $0.99^{b}$ & 0.04 & $1 \cdot 11^{\mathrm{b}}$ & 0.32 & $1.40^{\mathrm{a}}$ & 0.23 & $<0.01$ & 0.02 & 0.06 \\
\hline Hmox 1 & 1.00 & 0.00 & 0.99 & 0.03 & 0.84 & 0.31 & 0.96 & 0.30 & 0.14 & 0.38 & 0.29 \\
\hline Gst & $1.00^{\mathrm{b}}$ & 0.00 & $1.01^{b}$ & 0.021 & $0.79^{c}$ & 0.25 & $1 \cdot 16^{a}$ & 0.26 & 0.62 & $<0.01$ & $<0.01$ \\
\hline Gpx1 & 1.00 & 0.00 & $1 \cdot 17$ & 0.04 & 0.93 & 0.04 & 1.59 & 0.08 & 0.99 & $<0.01$ & 0.08 \\
\hline Sod1 & 1.00 & 0.00 & 1.07 & 0.04 & 0.82 & 0.04 & 0.92 & 0.03 & 0.97 & 0.31 & 0.84 \\
\hline
\end{tabular}

NBW, normal birth weight rats; NC, normal birth weight rats fed diets supplemented with $400 \mathrm{mg} / \mathrm{kg}$ curcumin; IC, IUGR rats fed diets supplemented with $400 \mathrm{mg} / \mathrm{kg}$ curcumin; $B$, birth weight; $D$, dietary curcumin supplementation; $B \times D$, interaction between the corresponding parameters; Nfe2l2, nuclear factor, erythroid 2-like 2; Nqo1, $\mathrm{NAD}(\mathrm{P}) \mathrm{H}$ dehydrogenase, quinone 1; Hmox1, haeme oxygenase 1; Gst, glutathione S transferase; Gpx1, glutathione peroxidase 1; Sod1, superoxide dismutase 1.

a,b,c Mean values within a row with unlike superscript letters were significantly different when a significant interaction was observed $(P<0.05)$.

* Data were analysed by using two-factor ANOVA and Duncan's post hoc testing, where appropriate.

curcumin supplementation significantly decreased $(P<0 \cdot 05)$ the mRNA expression for $I l 1 b$, increased $(P<0.05)$ the mRNA expressions for $N f e 2 l 2, N q o 1$, Gst and Gpx1, and had a tendency to decrease $(P>0.05)$ the mRNA expressions for Tinfa and $I l 6$ and to increase $(P>0.05)$ the mRNA expressions for Hmox 1 and Sod1 in the IC group. A birth weight $\times$ dietary interaction effect was noted for the mRNA expressions for Gst $(P=0 \cdot 001)$ in the liver of rats.

\section{Phosphorylation levels of $I \kappa B \alpha, N F-\kappa B$, Janus kinase 2 and} signal transducer and activator of transcription 3

The IUGR rats exhibited higher $(P<0.05)$ phosphorylated $\mathrm{I} \kappa \mathrm{B} \alpha$ (Fig. 6) and nuclear phosphorylated NF- $\kappa \mathrm{B}$ (Fig. 7) levels and lower $(P<0.05)$ cytoplasmic phosphorylated NF- $\kappa$ B (Fig. 8) levels in the liver than in the NBW rats. In addition, the phosphorylated levels of JAK2 (Fig. 9) and STAT3 (Fig. 10) were higher $(P=0 \cdot 24$, $P=0.01)$ in the IUGR rats than in the NBW and NC groups. Dietary curcumin supplementation decreased the phosphorylated

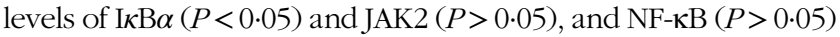
in the nucleus and cytoplasm of liver in the IC group.

\section{Discussion}

Globally, the number of underweight children was 113.4 million in $2015^{(26)}$. It has been widely accepted that early fetal life in the maternal uterus has long-term influences on offspring after birth in a variety of ways ${ }^{(27)}$. Finding an effective treatment of IUGR has become one of the more important challenges for human health.

Numerous studies revealed that poor maternal nutrition was one of the main reasons for smaller offspring in animals ${ }^{(28)}$ and 


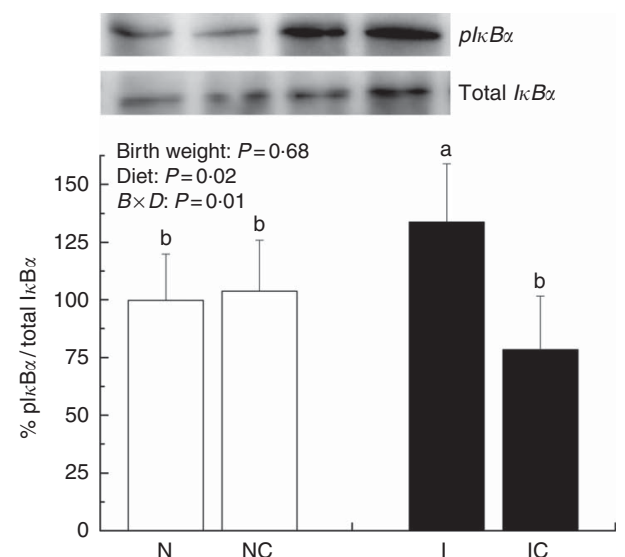

Fig. 6. Abundance of phosphorylated $I \kappa B a$ in liver of normal birth weight rats $(\mathrm{N})$, normal birth weight $(\square)$ rats supplemented with curcumin (NC), intrauterine growth retardation (IUGR, $\square$ ) rats (I) and IUGR rats supplemented with curcumin (IC) (12 weeks of age). $B$, birth weight; $D$, diet; $B \times D$, interaction between the corresponding parameters. Results were corrected for cytoplasmic protein, $n$ 6/group. ${ }^{\text {a,b }}$ Mean values with unlike letters were significantly different when a significant interaction was observed $(P<0.05)$.

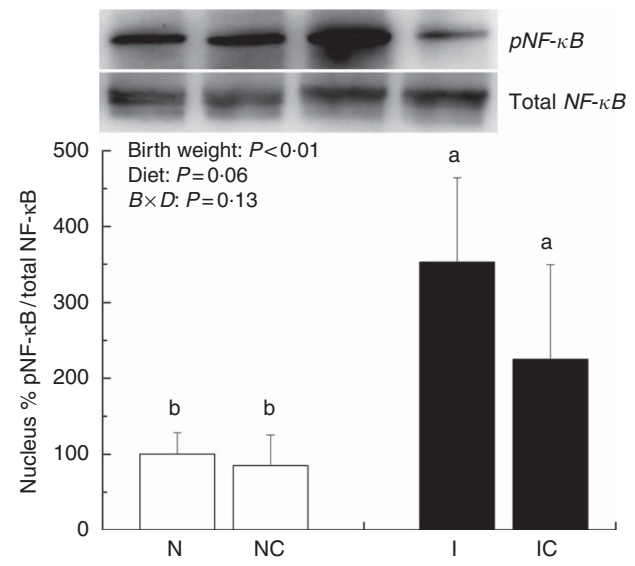

Fig. 7. Abundance of phosphorylated NF-KB in the nucleus of normal birth weight $(\square)$ rats (N), normal birth weight rats supplemented with curcumin (NC), intra-uterine growth retardation (IUGR, $\square$ ) rats (I) and IUGR rats supplemented with curcumin (IC) (12 weeks of age). $B$, birth weight; $D$, diet; $B \times D$, interaction between the corresponding parameters. Results were corrected for nuclear protein, $n 6 /$ group. ${ }^{\mathrm{a}, \mathrm{b}}$ Mean values with unlike letters were significantly different when a significant interaction was observed $(P<0.05)$.

humans ${ }^{(26)}$. In this study, rats were subjected to a $50 \%$ food restriction from day 10 of pregnancy. A low birth weight was regarded as an important feature of $\mathrm{IUGR}^{(2)}$. Body weight of IUGR rats was lower than those of NBW rats from $1 \mathrm{~d}$ to 12 weeks of age. The results implied that the restriction of fetal nutrient intake during pregnancy delayed postnatal catch-up growth in early life ${ }^{(19)}$. At 12 weeks of age, liver weight and its relative weight in IUGR rats were still lower than those in the NBW group, and were not improved by dietary curcumin supplementation. However, the body weights of IUGR and NBW rats slightly increased after treatment with curcumin. Early studies found that dietary administration with curcumin could alleviate the negative effects on growth caused by environmental factors ${ }^{(29,30)}$. In recent years, Jun et al. ${ }^{(31)}$ found that dietary curcumin supplementation had no influence on the

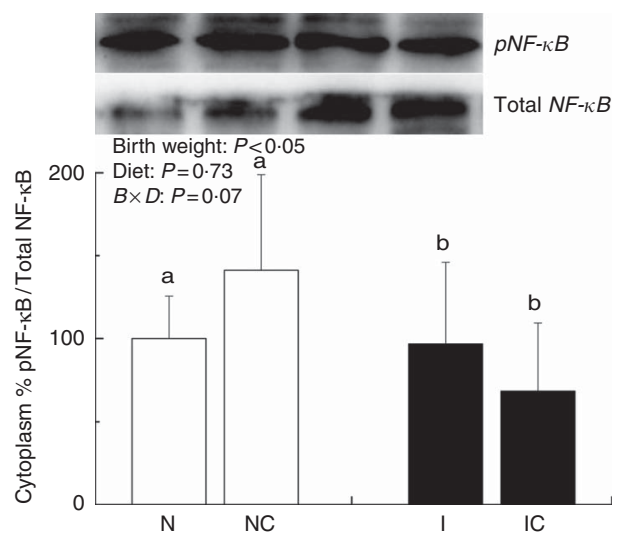

Fig. 8. Abundance of phosphorylated NF- $k B$ in the cytoplasm of normal birth weight $(\square)$ rats $(N)$, normal birth weight rats supplemented with curcumin (NC), intra-uterine growth retardation (IUGR, $\square$ ) rats (I) and IUGR rats supplemented with curcumin (IC) (12 weeks of age). $B$, birth weight; $D$, diet; $B \times D$, interaction between the corresponding parameters. Results were corrected for nuclear protein, $n 6 /$ group. ${ }^{\mathrm{a}, \mathrm{b}}$ Mean values with unlike letters were significantly different when a significant interaction was observed $(P<0.05)$.

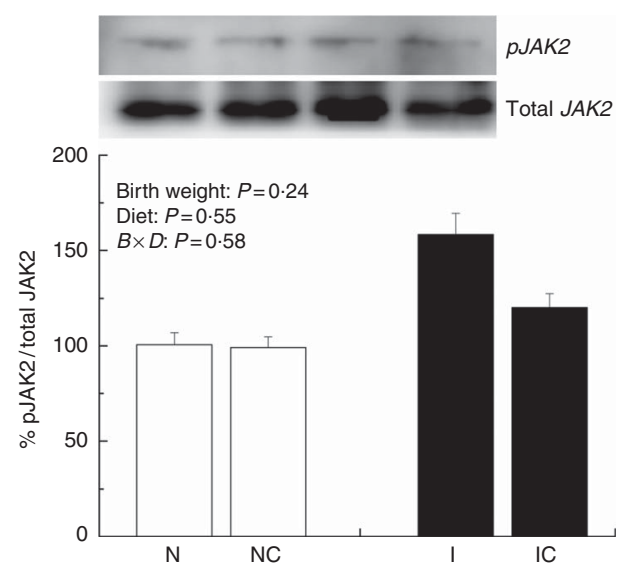

Fig. 9. Abundance of phosphorylated Janus kinase 2 (JAK2) in liver of normal birth weight rats $(N)$, normal birth weight $(\square)$ rats supplemented with curcumin (NC), intra-uterine growth retardation (IUGR, $\square$ ) rats (I) and IUGR rats supplemented with curcumin (IC) (12 weeks of age). $B$, birth weight; $D$, diet; $B \times D$, interaction between the corresponding parameters. Results were corrected for total protein, $n$ 6/group.

growth of rats. Further studies are necessary to investigate whether dietary curcumin supplementation has a beneficial effect on the growth of IUGR rats, especially liver weight.

IUGR neonates are associated with a high risk of inflammation and oxidative stress ${ }^{(28)}$. TNF- $\alpha$ is a key immune modulator, which can activate chemotactic cytokines and produce free radicals, leading to oxidative stress ${ }^{(32)}$. Furthermore, TNF- $\alpha$, IL- $1 \beta$ and IL- 6 have been implicated as prototype proinflammatory cytokines in the pathogenesis of sepsis ${ }^{(33)}$. Higher TNF- $\alpha$, IL- $1 \beta$ and IL-6 levels were observed in the serum of IUGR rats, which implied that pro-inflammation occurred in the body. Reports had demonstrated that a strong proinflammatory bias existed in IUGR with placental insufficiency $^{(8)}$. Significantly high concentrations of TNF- $\alpha$, IL- $1 \beta$ and IL-6 in IUGR rats were significantly decreased after dietary curcumin supplementation, suggesting that curcumin could 


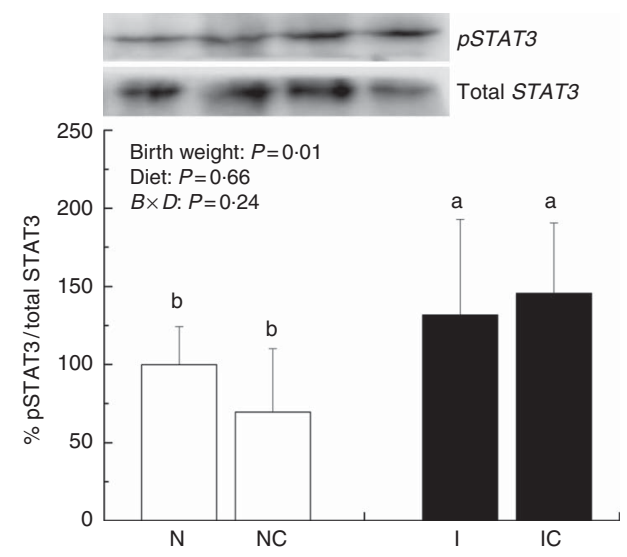

Fig. 10. Abundance of phosphorylated signal transducer and activator of transcription 3 (STAT3) in liver of normal birth weight rats (N), normal birth weight $(\square)$ rats supplemented with curcumin (NC), intra-uterine growth retardation (IUGR, $\square$ ) rats $(\mathrm{I})$ and IUGR rats supplemented with curcumin (IC) (12 weeks of age). $B$, birth weight; $D$, diet; $B \times D$, interaction between the corresponding parameters. Results were corrected for total protein, $n 6 /$ group. a,b Mean values with unlike letters were significantly different when a significant interaction was observed $(P<0.05)$

reduce inflammatory responses in the serum. These results are similar to those of previous studies in cells ${ }^{(34)}$ and rats $^{(35)}$. The liver is an important organ, and liver dysfunction has been observed in IUGR newborn pigs ${ }^{(7)}$. The activities of AST and ALT are positively correlated with portal flow ${ }^{(36)}$. Hepatic ALT is usually located in the cytoplasm, whereas AST is distributed in the cytoplasm and mitochondrial fractions. However, when the structure of the liver is seriously damaged, ALT and AST are released into the circulatory system, resulting in the improvement of ALT and AST activity in the serum ${ }^{(37)}$. In this study, the activities of serum AST and ALT in the IUGR group were higher than those in the NBW group. The increased activities of serum ALT and AST are generally accepted biomarkers for hepatic dysfunction $^{(38)}$. The vacuolisation and cell oedema from the histological examination of liver sections were prevalent in hepatocytes of IUGR rats, which revealed histological damage in the liver of IUGR rats. Meanwhile, fat cells also had mild denaturation. Similar to our findings, IUGR fetuses had a higher activity of glutamate oxaloacetate transaminase and impaired liver function than the normal ones ${ }^{(39)}$. After curcumin supplementation, the abnormal levels of serum AST and ALT and liver histological damage improved, and these results were not different from those observed in the normal condition. Previous studies had shown that curcumin could significantly reduce the levels of serum AST and ALT ${ }^{(40)}$ and liver injury in mice ${ }^{(16)}$ and rats $^{(22)}$. Our findings indicated that diets supplemented with curcumin attenuated liver injury and inflammation in IUGR rats. Thus, we concluded that the protective effects of curcumin on the liver may be very important in IUGR rats. To investigate the immunomodulatory mechanisms of curcumin, we detected the expressions of the NF- $\kappa \mathrm{B}$ and JAK/STAT pathways in the liver. NF- $\kappa \mathrm{B}$ is found in cytoplasm bound to $\mathrm{I} \kappa \mathrm{B}$. In response to various stimuli, including cytokines, stress and bacterial pathogens, the latent cytoplasmic NF- $\kappa \mathrm{B} / \mathrm{I} \kappa \mathrm{B}$ complex is activated by phosphorylation ${ }^{(41)}$. Phosphorylation of $\mathrm{I} \kappa \mathrm{B}$ induces their ubiquitination, proteosome degradation and, subsequently, NF- $\kappa \mathrm{B}$ release and nucleus translocation ${ }^{(42)}$. $\mathrm{NF}-\kappa \mathrm{B}$ is one of the most ubiquitous eukaryotic transcription factors that regulate the expression of genes associated with control of inflammatory responses, cellular proliferation/growth, cell adhesion and other processes ${ }^{(43)}$. Our results showed that IUGR induced increased levels of phosphorylated $\mathrm{I} \kappa \mathrm{B} \alpha$ and nuclear NF- $\kappa \mathrm{B}$ and decreased levels of cytoplasmic phosphorylated NF- $\kappa \mathrm{B}$ in the liver. Similar to our study, Zhong et al. ${ }^{(44)}$ also reported that the IкB was activated and the expression of $\mathrm{NF}-\kappa \mathrm{B}$ was increased by IUGR. These results suggested that the activation of the NF- $\kappa \mathrm{B} / \mathrm{I} \kappa \mathrm{B}$ complex might be related to increased levels of cytokines in IUGR, including TNF- $\alpha$ and IL- $1 \beta$. The JAK2/STAT3 pathway is known to be involved in the immune response of numerous cytokines, including IL-6, and activated in response to injury ${ }^{(45)}$. Our results demonstrated that IUGR induced high levels of phosphorylated JAK2 and STAT3 in the liver. The activation of the JAK/STAT3 pathway might be the result of increased IL- 6 in IUGR rats. Our results also showed that expression levels of $T n f a, I l 1 b$ and $I l 6$ were up-regulated in the liver of IUGR rats. Importantly, dietary curcumin supplementation obviously inhibited the phosphorylation levels of the $\mathrm{NF}-\kappa \mathrm{B}$ pathway and JAK2 in IUGR rats and down-regulated the expression of those downstream genes. These observations supported that curcumin attenuated inflammation through the $\mathrm{NF}-\kappa \mathrm{B}^{(35,46)}$ and JAK/STAT pathways ${ }^{(47)}$ in the liver of IUGR rats, which resulted in the negative regulation of cytokines (TNF- $\alpha$ ) and pro-inflammatory interleukins (IL- $1 \beta$ and IL-6) ${ }^{(48)}$.

Oxidative stress results from the imbalance of oxidation and antioxidation and appeared in patients with $\mathrm{IUGR}^{(49)}$. Overproduction of free oxygen radicals leads to lipid peroxidation and becomes one of the important reasons for cell damage. MDA is the primary product of lipid peroxidation. PC are used as markers of protein oxidation in the liver ${ }^{(50)}$. For the measurement of endogenous oxidative DNA damage, 8-OHDG has been used widely. In this study, we observed that the concentrations of MDA, PC and 8-OHDG in the liver of IUGR rats were significantly higher than those of NBW rats. The activities of T-AOC and SOD can validly reflect the antioxidant status of body and tissue. The IUGR group significantly decreased the activities of T-AOC and SOD in our study. GSH is one of the most important intracellular antioxidants that could eliminate lipid peroxides and repair oxidative proteins through a reaction catalysed by $\mathrm{GPX}^{(51)}$. During these reactions, GSH is converted to its disulphide form, GSSG. Under normal conditions, GSSG is reduced back to GSH by GR. GR is also an important intracellular antioxidant enzyme and can protect the cell against oxidative stress ${ }^{(52)}$. Our results showed that the IUGR group significantly decreased the concentration of GSH and activities of GR and GPX and increased the concentration of GSSG and value of GSSG/GSH in the liver. Furthermore, the concentration of GSH and activity of GPX were decreased in the serum of IUGR rats. These data strongly implied that IUGR rats caused lipid, protein and DNA damage and were susceptible to oxidative stress. During severe oxidative stress, the decreased GSH concentration and increased GSSG concentration induced an increase in the GSSG/GSH cycle ${ }^{(53)}$. Lower activities of GR and GPX might be another reason for GSSG failing to reduce GSH in the liver of IUGR rats. The findings were consistent with the results reported by Zhang et $a l .{ }^{(54)}$, who noted that the metabolic 
efficiency of the hepatic GSH redox cycle was decreased in IUGR piglets. Previous studies had proved that IUGR neonates could only weakly protect against oxidative stress ${ }^{(55)}$. Curcumin is an antioxidant used to protect against oxidative stress in mice experiments ${ }^{(56)}$. However, investigations on the effect of curcumin on oxidative stress and antioxidant defence in IUGR rats are very limited. In this study, our results revealed that dietary curcumin supplementation significantly decreased the concentrations of hepatic MDA, PC and 8-OHDG and slightly increased the activities of hepatic T-AOC and SOD in IUGR rats, which were in agreement with the results of previous studies ${ }^{(57)}$. Curcumin supplementation also efficiently improved the hepatic GSH redox cycle in IUGR rats. A study similar to this one was performed by Altintoprak $^{(58)}$, who demonstrated that dietary curcumin supplementation had beneficial effects on the hepatic antioxidant defence capacity of IUGR rats. A report showed that curcumin could attenuate As-induced hepatic oxidative stress by activating the $N f e 2 l 2$ pathway ${ }^{(59)}$. The $N f e 2 l 2$ is a key transcription factor that regulates the transcription of some antioxidant-related genes through the $N f e 2 l 2 /$ antioxidant response element (ARE) pathway $^{(60)}$. In this study, Nfe2l2 mRNA expression was downregulated in the liver of IUGR rats. Diets supplemented with curcumin increased the hepatic $N f e 2 l 2$ mRNA expression by $27 \cdot 26 \%$. The expression of antioxidant genes involved in the Nfe2l2/ARE pathway (Nqo1, Hmox1, Gst, Gpx1 and Sod1) were increased by curcumin supplementation in IUGR rats. The findings of this study were in agreement with previous observations that the hepatic $N f e 2 l 2$ protein and two typically recognised Nfe2l2 downstream genes, Nqo1 and Hmox1, were consistently up-regulated in curcumin-treated mice ${ }^{(59)}$. These results may indicate that curcumin protected IUGR rats from antioxidant stress by activating the expression of $N f e 2 l 2$ and downstream genes ${ }^{(61)}$.

In conclusion, maternal nutrition deficiency reduced the growth of rats in utero, leading to a low birth weight and delayed catch-up growth in early life. IUGR rats exhibited a high risk of inflammation and oxidative damage in the liver. Diets supplemented with curcumin could efficiently attenuate the inflammation and hepatic injury of IUGR rats by regulating the NF- $\kappa \mathrm{B}$ and JAK/STAT pathways, and enhance hepatic antioxidation capacity by activating expressions of $N f e 2 l 2$ and downstream genes. Our findings may be helpful in finding a new strategy for the early treatment of IUGR in humans in future.

\section{Acknowledgements}

The authors thank Kehu Bio-technology Research Center (Guangzhou, China) for kindly supplying the curcumin.

This study was supported by the grants from the National Natural Science Foundation of China (grant nos 31572418, 31472129 and 31601948).

The authors' responsibilities were as follows: J. H. designed the research, conducted research, analysed data and wrote the manuscript; Y. N. conducted the research, and wrote and revised the manuscript; C. W., L. Z., X. Z. and J. Z. designed the research; F. W., T. C. and K. B. conducted the research; and T. W. had primary responsibility for final content. All authors read and approved the final manuscript.

The authors declare that there are no conflicts of interest.

\section{References}

1. De OM, Blossner M, Villar J, et al. (1998) Levels and patterns of intrauterine growth retardation in developing countries. Eur J Nutr 52, Suppl. 1, S5-S15.

2. Hay WW, Thureen PJ \& Anderson MS (2001) Intrauterine growth restriction. NeoReviews 2, e129-e138.

3. Varvarigou AA (2010) Intrauterine growth restriction as a potential risk factor for disease onset in adulthood. $J$ Pediatr Endocrinol Metab 23, 215-224.

4. Barker DJ, Eriksson JG, Forsen T, et al. (2002) Fetal origins of adult disease: strength of effects and biological basis. Int $J$ Endocrinol 31, 1235-1239.

5. Mcmillen IC \& Robinson JS (2005) Developmental origins of the metabolic syndrome: prediction, plasticity, and programming. Physiol Rev 85, 571-633.

6. Hales CN \& Barker DJ (2001) The thrifty phenotype hypothesis. Br Med Bull 60, 5-20.

7. Junjun W, Lixiang C, Defa L, et al. (2008) Intrauterine growth restriction affects the proteomes of the small intestine, liver, and skeletal muscle in newborn pigs. J Nutr 138, 60-66.

8. Raghupathy R, Al-Azemi M \& Azizieh F (2012) Intrauterine growth restriction: cytokine profiles of trophoblast antigenstimulated maternal lymphocytes. Clin Dev Immunol 2012, 734865 .

9. Aggarwal BB, Sundaram C, Malani N, et al. (2007) Curcumin: the Indian solid gold. Adv Exp Med Biol 595, 1-75.

10. Miłobȩdzka J, Kostanecki Sv \& Lampe V (1910) Zur kenntnis des curcumins (Knowledge of curcumins). Eur J Inorg Chem 43, 2163-2170.

11. Ghorbani Z, Hekmatdoost A \& Mirmiran P (2014) Antihyperglycemic and insulin sensitizer effects of turmeric and its principle constituent curcumin. Int J Endocrinol Metab 12, e18081.

12. Wang ME, Chen YC, Chen IS, et al. (2012) Curcumin protects against thioacetamide-induced hepatic fibrosis by attenuating the inflammatory response and inducing apoptosis of damaged hepatocytes. J Nutr Biochem 23, 1352-1366.

13. Somparn P, Phisalaphong C, Nakornchai S, et al. (2007) Comparative antioxidant activities of curcumin and its demethoxy and hydrogenated derivatives. Biol Pharm Bull 30, 74-78.

14. Ruby AJ, Kuttan G, Babu KD, et al. (1995) Anti-tumour and antioxidant activity of natural curcuminoids. Cancer Lett $\mathbf{9 4}$, 79-83.

15. Mazidi M, Karimi E, Meydani M, et al. (2016) Curcumin. World J Methodol 6, 112-117.

16. Zhang J, Xu L, Zhang L, et al. (2014) Curcumin attenuates d-galactosamine/lipopolysaccharide-induced liver injury and mitochondrial dysfunction in mice. J Nutr 144, 1211-1218.

17. Molina-Jijon E, Tapia E, Zazueta C, et al. (2011) Curcumin prevents $\mathrm{Cr}(\mathrm{VI})$-induced renal oxidant damage by a mitochondrial pathway. Free Radic Biol Med 51, 1543-1557.

18. Kowluru RA \& Kanwar M (2007) Effects of curcumin on retinal oxidative stress and inflammation in diabetes. Nutr Metab 4, 1-8.

19. Desai M, Gayle D, Babu J, et al. (2005) Programmed obesity in intrauterine growth-restricted newborns: modulation by newborn nutrition. Am J Physiol Regul Integr Comp Physiol 288, R91-R96.

20. Widdowson EM \& McCance RA (1975) A review: new thoughts on growth. Pediatr Res 9, 154-156.

21. Reeves PG, Nielsen FH \& Fahey GC Jr (1993) AIN-93 purified diets for laboratory rodents: final report of the American Institute of Nutrition ad boc writing committee on the reformulation of the AIN-76A rodent diet. J Nutr 123, 1939-1951. 
22. Toydemir T, Kanter M, Erboga M, et al. (2015) Antioxidative, antiapoptotic, and proliferative effect of curcumin on liver regeneration after partial hepatectomy in rats. Toxicol Ind Health 31, 162-172.

23. Caprau DM, O'Grady SP, Callaway CW, et al. (2007) IUGR alters IGF1 receptor gene expression, DNA methylation and histones acetylation in the brain. Early Hum Dev 83, 547 .

24. He J, Dong L, Xu W, et al. (2015) Dietary tributyrin supplementation attenuates insulin resistance and abnormal lipid metabolism in suckling piglets with intrauterine growth retardation. PLOS ONE 10, e0136848.

25. Schmittgen TD \& Livak KJ (2008) Analyzing real-time PCR data by the comparative C(T) method. Nat Protoc 3, 1101-1108.

26. Onis MD, Blössner M, Borghi E, et al. (2004) Estimates of global prevalence of childhood underweight in 1990 and 2015. JAMA 291, 2600-2606.

27. Aiken CE \& Ozanne SE (2013) Transgenerational developmental programming. Hum Reprod Update 20, 63-75.

28. Tarryadkins JL, Fernandeztwinn DS, Hargreaves IP, et al. (2015) Coenzyme $Q_{10}$ prevents hepatic fibrosis, inflammation, and oxidative stress in a male rat model of poor maternal nutrition and accelerated postnatal growth. Am J Clin Nutr 103, 579-588.

29. Sahin K, Orhan C, Tuzcu Z, et al. (2012) Curcumin ameloriates heat stress via inhibition of oxidative stress and modulation of Nrf2/HO-1 pathway in quail. Food Chem Toxicol 50 , 4035-4041.

30. Zhang JF, Hu ZP, Lu CH, et al. (2015) Dietary curcumin supplementation protects against heat-stress-impaired growth performance of broilers possibly through a mitochondrial pathway. J. Anim. Sci 93, 1656-1665.

31. He JH, Xie H \& Wu S (2016) Dietary supplementation of curcumin alleviates NF-кB-dependent skeletal muscle wasting in rat. Endocr Metab Immune Disord Drug Targets 16, 140-147.

32. Starke RM, Daniel MS \& Dumont RMAS (2014) Tumor necrosis factor- $\alpha$ modulates cerebral aneurysm formation and rupture. Alcohol Clin Exp Res 5, 269-277.

33. Deventer SJHv (2000) Cytokine and cytokine receptor polymorphisms in infectious disease. Intensive Care Med 26, S98-S102.

34. Liu L, Shang Y, Li M, et al. (2015) Curcumin ameliorates asthmatic airway inflammation by activating nuclear factor-E2related factor 2 /haem oxygenase (HO)-1 signalling pathway. Clin Exp Pharmacol Physiol 42, 520-529.

35. Soetikno V, Sari FR, Veeraveedu PT, et al. (2011) Curcumin ameliorates macrophage infiltration by inhibiting NF- $\mathrm{KB}$ activation and proinflammatory cytokines in streptozotocin induced-diabetic nephropathy. Nutr Metab 8, 35.

36. Kuo PC, Li K, Alfrey EJ, et al. (1995) Magnetic resonance imaging and hepatic hemodynamics: correlation with metabolic function in liver transplantation candidates. Surgery $\mathbf{1 1 7}$ 373-379.

37. Nyblom H, Berggren U, Balldin J, et al. (2004) High ast/alt ratio may indicate advanced alcoholic liver disease rather than heavy drinking. Alcohol Alcobol 39, 336-339.

38. Tang Y, Chao G, Xing M, et al. (2012) Quercetin prevents ethanol-induced dyslipidemia and mitochondrial oxidative damage. Food Chem Toxicol 50, 1194-1200.

39. Liu C, Lin G, Wang $\mathrm{X}$, et al. (2013) Intrauterine growth restriction alters the hepatic proteome in fetal pigs. $J$ Nutr Biochem 24, 954-959.

40. Zhao HL, Song CH \& Chai OH (2012) Negative effects of curcumin on liver injury induced by alcohol. Phytother Res $\mathbf{2 6}$, 1857-1863.
41. Hiscott J, Kwon H \& Genin P (2001) Hostile takeovers: viral appropriation of the NF-kB pathway. J Clin Invest $\mathbf{1 0 7}$, 143-151.

42. Echeverri R, Nancy P \& Mockus S (2008) Factor nuclear $\kappa B$ (NF-кB): signalosoma y su importancia en enfermedades inflamatorias y cancer (Nuclear factor $\kappa \mathrm{B}(\mathrm{NF}-\kappa \mathrm{B})$ : signalosome and its importance in inflammatory diseases and cancer). Rev Fac Med 56, 133-146.

43. Chen F, Castranova V, Shi X, et al. (1999) New insights into the role of nuclear factor- $\mathrm{\kappa B}$, a ubiquitous transcription factor in the initiation of diseases. Clin Chem 45, 7-17.

44. Zhong X, Li W, Huang X, et al. (2012) Effects of glutamine supplementation on the immune status in weaning piglets with intrauterine growth retardation. Arch Anim Nutr 66, 347-356.

45. Yang X, He G, Hao Y, et al. (2010) The role of the JAK2STAT3 pathway in pro-inflammatory responses of EMFstimulated N9 microglial cells. J Neuroinflammation 7, 54.

46. Surh YJ, Chun KS, Cha HH, et al. (2001) Molecular mechanisms underlying chemopreventive activities of antiinflammatory phytochemicals: down-regulation of COX-2 and iNOS through suppression of NF-kappa B activation. Mutat Res 480-481, 243-268.

47. Kim HY, Park EJ, Joe EH, et al. (2003) Curcumin suppresses Janus kinase-STAT inflammatory signaling through activation of Src homology 2 domain-containing tyrosine phosphatase 2 in brain microglia. J Immunol 171, 6072-6079.

48. Reyes-Gordillo K, Segovia J, Shibayama M, et al. (2007) Curcumin protects against acute liver damage in the rat by inhibiting NF- $\mathrm{KB}$, proinflammatory cytokines production and oxidative stress. Biochim Biophys Acta 1770, 989-996.

49. Centini G, Kenanidis A, Rosignoli L, et al. (2004) Intrauterine oxidative stress and doppler flussimetry in fetuses with IUGR. Ultrasound Obstet Gynecol 24, 314.

50. Chaudhuri AR, de Waal EM, Pierce A, et al. (2006) Detection of protein carbonyls in aging liver tissue: a fluorescence-based proteomic approach. Mech Ageing Dev 127, 849-861.

51. Fang YZ, Yang S \& Wu G (2002) Free radicals, antioxidants, and nutrition. Nutrition 18, 872-879.

52. Mahmoud KZ \& Edens FW (2003) Influence of selenium sources on age-related and mild heat stress-related changes of blood and liver glutathione redox cycle in broiler chickens (Gallus domesticus). Comp Biochem Physiol B Biochem Mol Biol 136, 921-934.

53. Jones DP (2002) Redox potential of GSH/GSSG couple: assay and biological significance. Methods Enzymol 348, 93-112.

54. Zhang $\mathrm{H}$, Chen $\mathrm{Y}$, Li $\mathrm{Y}$, et al. (2014) Medium-chain TAG attenuate hepatic oxidative damage in intra-uterine growth-retarded weanling piglets by improving the metabolic efficiency of the glutathione redox cycle. Br J Nutr $\mathbf{1 1 2}$, 876-885.

55. Hracsko Z, Orvos H, Novak Z, et al. (2013) Evaluation of oxidative stress markers in neonates with intra-uterine growth retardation. Redox Rep 13, 11-16.

56. Wen PL, Xue TM, Yu W, et al. (2015) Zn(II)-curcumin protects against oxidative stress, deleterious changes in sperm parameters and histological alterations in a male mouse model of cyclophosphamide-induced reproductive damage. Environ Toxicol Pharmacol 39, 515-524.

57. Suryanarayana P, Satyanarayana A, Balakrishna N, et al. (2007) Effect of turmeric and curcumin on oxidative stress and antioxidant enzymes in streptozotocin-induced diabetic rat. Med Sci Monit 13, BR286-BR292.

58. Altıntoprak N, Kar M, Acar M, et al. (2016) Antioxidant activities of curcumin in allergic rhinitis. Eur Arch Otorbinolaryngol 273, 3765-3773. 
59. Gao S, Duan X, Wang X, et al. (2013) Curcumin attenuates arsenic-induced hepatic injuries and oxidative stress in experimental mice through activation of Nrf2 pathway, promotion of arsenic methylation and urinary excretion. Food Chem Toxicol 59, 739-747.
60. Kensler TW, Wakabayashi N \& Biswal S (2007) Cell survival responses to environmental stresses via the Keap1-Nrf2-ARE pathway. Annu Rev Pharmacol 47, 89-116.

61. Li W \& Kong AN (2009) Molecular mechanisms of Nrf2mediated antioxidant response. Mol Carcinog 48, 91-104. 